\title{
The Evaluation of Medical Conditions in Patients Admitted to the Oral Diagnosis Clinic
}

\begin{abstract}
SUMMARY
Background/Aim: The aim of this study is to set forth the current systemic diseases of the patients admitted to the oral diagnosis clinic of the Faculty of Dentistry Sütçü Imam University, and the prevalence of these diseases. Material and Methods: This study will be conducted by retrospective evaluation of anamneses in the tooth information management system of patients admitted to the oral diagnosis clinic of the Faculty of Dentistry, Sütçü Imam University for dental treatment. The anamneses taken from the patients before their treatments will be obtained from digital medium. Results: Out of 4077 patients included in the study, 2554 were female, and 1523 were male. Of them, 25.6\% had systemic diseases. The mean age of the patients was $35.24 \%+12.3$. It was found that cardiovascular diseases were more common than the other systemic diseases. The most common cardiovascular disease was found to be hypertension (7.5\%), while the most common endocrine system disease was diabetes mellitus (7.5\%). Conclusions: Dental practitioners must keep themselves up-to-date as they encounter patients with systemic diseases. They must pay attention while taking anamneses from patients. Therefore, they may apply medical consultation to prevent probable complications when necessary.
\end{abstract}

Key words: Systemic Disease, Anamnesis, Dental Treatment

\author{
Katibe Tuğçe Temur \\ Department of Oral and Maxillofacial Radiology, \\ Faculty of Dentistry, \\ Niğde Ömer Halisdemir University, Niğde, \\ Turkey
}

\section{ORIGINAL PAPER (OP)}

Balk J Dent Med, 2021;129-133

\section{Introduction}

Dental practitioners should be competent enough to treat medically-threatened people and have advanced awareness for treatment procedures of various systematic diseases. Medical emergencies may occur during or after dental procedures and have serious results. It is necessary to take anamnesis before dental treatment to provide appropriate dental treatment for patients. The dental treatment of a patient should be done according to the patient's medical needs.

Knowledge and awareness of the patient's medical profile is important for the safe management of the patient ${ }^{1-3}$. Accordingly, dental treatment may need to be adjusted based on the patient's medical restrictions, and doctor consultation may be necessary sometimes ${ }^{4}$.

The dental practitioner should be familiar with cardiovascular, respiratory, immunity, endocrine, and metabolic diseases to treat these patients accurately. Patients with immunosuppression, cancer, HIV, hepatitis, and patients using blood thinners may require special dental treatment ${ }^{5,6}$.

Also, it is necessary to search for the prevalence of systemic diseases among dental patients in various geographical regions ${ }^{7,8}$. Some studies in the literature stated that half of the patients who were transferred to faculties of dentistry developed at least one medical complication $^{9,10}$.

Besides, oral symptoms generally appear as the first indicators of a systemic condition in most of the systemic diseases ${ }^{11}$. Dental practitioners should pay attention to this condition. Thus, dentists can contribute to the diagnosis of some systemic diseases ${ }^{12}$. Additionally, systemic diseases may strain the patient's tolerance for dental interventions or sometimes limit the patient's ability to maintain oral hygiene care ${ }^{13}$

The aim of this study is to set forth the current systemic diseases of the patients admitted to the oral diagnosis clinic of the Faculty of Dentistry, Sütçü İmam University, and the prevalence of these diseases. 


\section{Material and Methods}

This study was conducted by retrospective evaluation of anamneses in the tooth information management system of patients admitted to the oral diagnosis clinic of the Faculty of Dentistry, Sütçü İmam University for dental treatment. The anamneses taken from the patients before their treatments were obtained from the digital medium. This study was approved by Sütçü İmam University Faculty of Medicine Clinical Research Ethics Committee (Decision Numbered 5 Dated 11.12.2019).

The evaluation included the patients with cardiovascular diseases (hypertension myocardial infarction, cardiac failure, others), respiratory system diseases (chronic obstructive pulmonary disease, asthma, others) endocrine system diseases (diabetes mellitus, thyroid disorders, others), malign diseases, neurologic and psychological diseases (epilepsy, MS, others) infection diseases (hepatitis, HIV), gastrointestinal diseases (gastritis, ulcer, other), and transplantation patients.

Data obtained were analyzed using the Statistical Package for the Social Sciences 23.0 version (SPSS INC., Chicago, 11., USA). The probability level was determined as $\alpha=0.05$ for the statistical significance. Pearson's Chisquare test was used to compare the data.

\section{Results}

Of 4077 patients included in the study, 2554 were female and 1523 were male. The number of healthy women was 1524 and the number of diseased women was 730 while the number of healthy men was 1208 and the number of diseased men was 315 (Figure 1). The study found that $21.3 \%$ of male and $28.5 \%$ of women had systemic diseases. No significant difference was found based on gender. Of the patients, $25.5 \%$ had a systemic disease (Table 1 and 2). The mean age of the patients was $35.24+12.3$ while the mean age of individuals with a systemic disease was $46 \pm 11.6$.

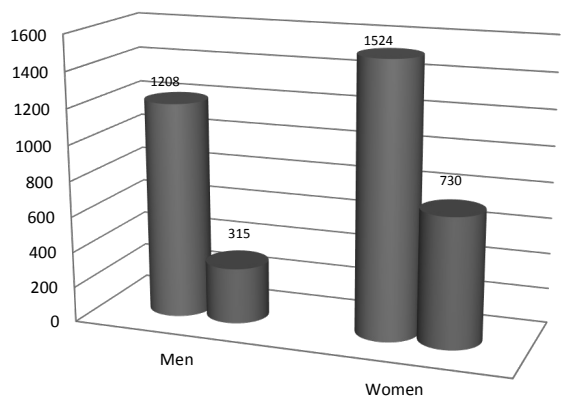

- Healthy individual - Diseased individual

Figure 1. Distribution of the disease according to sex
The study found that cardiovascular diseases were more common than other systemic diseases. The most common cardiovascular disease was hypertension (7.5\%) followed by endocrine system diseases. The most common endocrine system disease was found to be diabetes mellitus $(5.5 \%)$. Considering the respiration system diseases, the most common disease was found to be asthma $(2.2 \%)$. The frequency of neurological and psychiatric diseases was $(1.6 \%)$. The most common infectious disease was Hepatitis B (1.4\%) while the most common gastrointestinal system disease was gastritis (1.1\%). The occurrence prevalence of malign diseases was $0.8 \%$. The occurrence prevalence of transplantation patients was $0.3 \%$. Below is the frequency and percentage table of systemic diseases based on sex (Tables 1 and 2). The distribution of subgroups of systemic diseases is in Table 3 .

Table 1. Frequency and percentage of systemic diseases in men

\begin{tabular}{lcl}
\hline Men & $\mathrm{N}$ & $\%$ \\
\hline Cardiovascular Diseases & 100 & 6.56 \\
Respiratory System Diseases & 20 & 1.31 \\
Endocrine System Diseases & 84 & 5.51 \\
Malign Diseases & 18 & 1.18 \\
Neurologic \& Psychiatric Diseases & 20 & 1.31 \\
Infectious Diseases & 34 & 2.23 \\
Gastrointestinal Diseases & 33 & 2.16 \\
Transplantation Patients & 6 & 0.39 \\
\hline TOTAL & 315 & 21.3 \\
\hline
\end{tabular}

Table 2. Frequency and percentage of systemic diseases in women

\begin{tabular}{lrc}
\hline Women & $\mathrm{n}$ & $\%$ \\
\hline Cardiovascular Diseases & 276 & 10.8 \\
Respiratory System Diseases & 80 & 3.13 \\
Endocrine System Diseases & 225 & 8.08 \\
Malign Diseases & 44 & 1.72 \\
Neurologic \& Psychiatric Diseases & 47 & 1.84 \\
Infectious Diseases & 28 & 1.09 \\
Gastrointestinal Diseases & 27 & 1.05 \\
Transplantation Patients & 3 & 0.11 \\
\hline TOTAL & 730 & 28.5 \\
\hline
\end{tabular}


Table 3. Distribution of subgroups of systemic diseases

\begin{tabular}{lrl}
\hline Systemic Diseases & $\mathrm{N}$ & $\%$ \\
\hline Hypertension & 309 & 7.5 \\
Myocardial İnfarction & 10 & 0.24 \\
Cardiac Failure & 20 & 0.49 \\
Others & 37 & 0.90 \\
COPD & 6 & 0.14 \\
Asthma & 91 & 2.2 \\
Others & 3 & 0.07 \\
Diabetes Mellitus (Type1-2) & 225 & 5.5 \\
Tyroid Disorders & 75 & 1.83 \\
Others & 9 & 0.22 \\
Malign Diseases & 62 & 1.52 \\
Epilepsy & 30 & 0.73 \\
Multiple Sclerosis & 10 & 0.24 \\
Others & & \\
Hepatitis-B & 27 & 0.66 \\
HIV & 59 & 1.4 \\
Others & 1 & 0.02 \\
Gastritis & 2 & 0.04 \\
Ulser & 45 & 1.1 \\
Tthers & 10 & 0.24 \\
Transplantation Patients & 5 & 0.12 \\
TOTA & 9 & 0.22 \\
\hline
\end{tabular}

TOTAL 1,045

Chronic obstructive pulmonary disease (COPD)

\section{Discussion}

In the literature, the studies that evaluate the systemic conditions of patients who are admitted to dental practitioners have different results. The prevalence rate of systemic diseases was reported as $73 \%$ by Marham et al. ${ }^{14}, 48.2 \%$ by Kaur et al. ${ }^{15}, 11,7 \%$ by Oyetola et al. ${ }^{16}$, $35.2 \%$ by Gaphor et al. ${ }^{17}, 37.2 \%$ by de Jong et al. ${ }^{18}, 26 \%$ by Ciğerim $^{19}, 28.2 \%$ by Smeets et al. ${ }^{20}$, and $12.2 \%$ by Dhanuthai et $a l .{ }^{21}$. The prevalence of systemic disease was $25.5 \%$ in the present study.

Adequate record-keeping remains a challenge in health planning and management in developing societies. Many patients may not report honestly about their medical history, particularly because of the notion that there is no connection to their dental complaints, or their cultural and religious beliefs that forbid confession of a disease ${ }^{16,22}$. Geographical location differences may explain the difference in study results.

Some studies have shown that the prevalence of systemic diseases is higher in women ${ }^{4,14}$. Although the present study showed that systemic disease was more common in women, no significant difference was found based on sex. In the study of Ciğerim et al., the rate of systemic disease in men was found to be higher than in women ${ }^{19}$.

The most common disease among cardiovascular system diseases is hypertension. Hypertension was the most common disease in the study of Mesgarzadeh et al..$^{10}$. Similarly, Oyetola and Bhateja et al. also stated that cardiovascular diseases (Hypertension) rank first ${ }^{21,23}$. In parallel with the literature, the most common systemic disease in this study was hypertension. Contrary to these studies, in the study evaluating the patient population with periodontal disease, the most common medical conditions are diabetes mellitus and hormonal disorders ${ }^{24}$.

Dental practitioners should consider that systemic diseases may also cause oral symptoms, and should keep themselves up-to-date in terms of these diseases to prevent possible complications. Especially, it should be known that hypertensive patients may show symptoms such as gingivitis, periodontitis, lichenoid reactions, hyposalivation, and facial nerve paralysis. Facial nerve palsy is usually seen in malignant hypertensive patients. In patients with facial nerve palsy, clinical findings such as paralysis of the facial muscles, drooling, expressionless appearance of the face, inability to blow, eye opening, and continuous tears develop ${ }^{25}$.

The present study revealed that the second most common disease was endocrine system disease, and diabetes was the most common disease among them. In parallel with this study, it has been reported that the second most common endocrine system diseases are in the studies of Ciğerim and Aggarwal et al. ${ }^{19,26}$. Dental practitioners should know that diabetes mellitus may cause oral symptoms such as burning sensation in the mouth, candidiasis, cariosity, lichen planus, dysesthesia, and saliva function disorder ${ }^{27}$. In addition, as a result of high blood sugar, microvascular disease, susceptibility to infection and delayed wound healing can be seen. Consequently, healing may be affected by endosseous implant surgery in patients with diabetes ${ }^{28}$.

On the other hand in the study by Sachdeva, the most common diseases were gastrointestinal system diseases ${ }^{13}$. However, other system diseases were found to be less common than cardiovascular and endocrine systems diseases in the present study.

In the study of Al-Bayati et al., the frequency of asthma has been reported to be $5.8 \%{ }^{4}$. In the same study, it was reported that respiratory system diseases were less common than endocrine and cardiovascular diseases. Similarly, in this study, it was determined that the prevalence of asthma was $2.2 \%$ and respiratory system diseases were seen less frequently than cardiovascular diseases.

Leblebicioğlu et al. reported that HBV carrier rate is between $6-14.3 \%$ in Turkey according to serological 
markers $^{29}$. Hepatitis B $(1.5 \%)$ was the most common infectious disease in this study. The prevalence of HIV was $0.02 \%$. The low rate in the study may be due to the misrepresentation of the patients. The transmission of the disease both from patients to practitioners and vice versa when infection control measures are not applied is an important problem ${ }^{30}$. Dentists must follow strict sterilization procedure to prevent infection transmission in clinics.

The studies in the literature stated that the mean age of the patients with systemic diseases is higher than healthy individuals ${ }^{4,15,19}$. Similarly, the present study noted that the mean age of the patients with systemic diseases was higher than that of healthy individuals.

In addition, in this study, the frequency of malignant disease was $1.52 \%$, transplantation patient $0.22 \%$ and neurological and psychiatric diseases $1.6 \%$. Similar to this study, Ciğerim et al. ${ }^{19}$ study found that neurological and psychiatric diseases were less common in patients who applied for dental treatment. Additionally, the rate of malignant disease and organ failure has been reported to be $0.4 \%$.

\section{Conclusions}

Dental practitioners must keep themselves up-to-date as they encounter patients with systemic diseases. They must pay attention while taking anamnesis from patients. Therefore, they may apply a medical consultation to prevent probable complications when necessary.

\section{References}

1. Santhosh K, Roshna KR. Prevalence of systemic diseases in oral surgery patients in South Indian "population. Asian J Pharm Clin Res, 2016;9:304-307.

2. Amirchaghmaghi M, Pakfetrat A, Mosannen MP, Shafiee Z, Ghalavani H, Aghasizadeh D, et al. Medical risk assessment in patients referred to dental clinics, Mashhad, Iran (20112012). Open Dent J, 2015;9:420-425.

3. Berge TI. Oral surgery in Norwegian general dental practice-a survey. Extent, scope, referrals, emergencies, and medically compromised patients. Acta Odontol Scand, 1992;50:7-16.

4. Al-Bayaty HF, Murti PR, Naidu RS, Matthews D, Simeon D. Medical problems among dental patients at the School of Dentistry, the University of the West Indies. J Dent Educ, 2009;73:1408-1414.

5. Baumeister SE, Davidson PL, Carreon DC, Nakazono TT, Gutierrez JJ, Andersen RM. What influences dental students to serve special care patients? Spec Care Dent, 2007;27:15-22.
6. Gasco-García C, Cerero-Lapiedra R. Descriptive study of the patients treated at the clinic "integrated dentistry for patients with special needs" at Complutense University of Madrid (2003-2012). Med Oral Patol Oral Cir Bucal. 2015;20:211-217.

7. Parirokh M, Eghbal MJ, Ghoddusi J, Kakoei S, Haghdoost AA, Kakooei S. The frequency of medically compromised patients in endodontic offices in Iran. Iran Endod J, 2013;8:48-51.

8. Almas K, Awartani FA. Prevalence of medically compromised patients referred for periodontal treatment to a teaching hospital in Central Saudi Arabia. Saudi Med J, 2003;24:1242-1245.

9. Khader YS, Alsaeed O, Burgan SZ, Amarin ZO. Prevalence of medical conditions among patients attending dental teaching clinics in northern Jordan J. Contemp Dent Pract, 2007;8:60-67.

10. Mesgarzadeh A, Mahmood-Hashemi H, Sharifi R, Hasheminasab M, Karimi A. A retrospective study of medically compromised patients referred to the Department of Oral and Maxillofacial Surgery, School of Dentistry of Tehran University of Medical Science. Iran J Craniomax Res, 2014;1:11-16.

11. Güngör Hatipoğlu M, Hatipoğlu H . Evaluation of Medical Consultations Forms of a Patient Group Admitted to the Dental Clinic of a University. Ankara Med J, 2015;15:10-15.

12. Stegeman CA. Oral manifestations of diabetes. Home Healthc Nurse, 2005;23:233-240.

13. Sachdeva SK, Raj SS, Kaushik A, Sharma D, Verma KG, Dutta S, et al. Prevalence of Medical Problems among Patients Attending a Dental School in India-A Cross Sectional Study. OHDM, 2015;14:429-432.

14. Maryam A, Atessa P, Pegah MM, Zahra S, Hanieh G, Davood A, et al. Medical Risk Assessment in Patients Referred to Dental Clinics, Mashhad, Iran (2011-2012). Open Dent J, 2015;9:420-425.

15. Kaur J. Assessing the Medical Health Statistics of patients in a Dental Institute. J Adv Med Dent Scie Res, 2017;5:64-68.

16. Oyetola EO, Adesina OM, Ogunbameru K, Egunjobi S, Adejobi AF. Distribution of Medical Conditions among Dental Patients. Niger Med J, 2020;61:129-135.

17. Gaphor SM, Abdullah MJ. Medical Status and Medication Use in Patients Attending Shorish Private Dental Specialty in Sulaimani City. J Interdiscipl Med Dent Sci, 2014;2:130.

18. de Jong KJ, Oosting J, Peters GJ, Abraham-Inpijn L. Detecting medical problems in dentistry: a survey of 4,087 patients in The Netherlands. Eur J Med, 1992;1:23-29.

19. Ciğerim L. Medical Profile of Individuals Who Apply To Faculty of Dentistry. Van Med J, 2019;26:1-5.

20. Smeets EC, De Jong KJ, Abraham-Inpijn L. Detecting the medically compromised patient in dentistry by means of the medical risk related history: A survey of 29,424 dental patients in The Netherlands. Prev Med, 1998;27:530-535.

21. Dhanuthai K, Sappayatosok K, Bijaphala P, Kulvitit S, Sereerat T. Prevalence of medically compromised conditions in dental patients. Med Oral Patol Oral Cir Bucal, 2009;14:287-291.

22. Best M, Butow P, Olver I. Do patients want doctors to talk about spirituality? A systematic literature review. Patient Educ Couns, 2015;98:1320-1328. 
23. Bhateja S. High prevalence of cardiovascular diseases among other medically compromised conditions in dental patients: A retrospective study. J Cardiovasc Dis Res, 2012;3:113-116.

24. Javali MA, Khader MA, Al-Qahtani NA. Prevalence of selfreported medical conditions among dental patients. Saudi J Med Med Sci, 2017;5:238-241.

25. Kumar P, Mastan K, Chowdhary R, Shanmugam K. Oral manifestations in hypertensive patients: A clinical study. J Oral Maxillofac Pathol, 2012;16:215-221.

26. Aggarwal A, Panat SR, Talukder S. Self-reported medical problems among dental patients in Western Uttar Pradesh, India. J Dent Educ, 2011;75:1635-1640.

27. Bharateesh J, Ahmed M, Kokila G. Diabetes and Oral Health: A Case-control Study. Int J Prev Med, 2012;3:806-809.

28. Farzad P, Andersson L, Nyberg J. Dental implant treatment in diabetic patients. Implant Dent, 2002;11:262-267.

29. Leblebicioglu H, Eroglu C; Members of the Hepatitis Study Group. Acute hepatitis B virus infection in Turkey: epidemiology and genotype distribution. Clin Microbiol Infect, 2004; 10:537-541.
30. Mahboobi N, Agha-Hosseini F, Mahboobi N, Safari S, Lavanchy D, Alavian SM. Hepatitis B virüs infection in dentistry: a forgotten topic. J Viral Hepat, 2010;17:307-316.

Conflict of Interests: Nothing to declare.

Financial Disclosure Statement: Nothing to declare.

Human Rights Statement: All the procedures on humans were conducted in accordance with the Helsinki Declaration of 1975, as revised 2000. Consent was obtained from the patient/s and approved for the current study by national ethical committee.

Animal Rights Statement: None required.

Received on October 3, 2020.

Revised on December 2, 2020.

Accepted on January 20, 2021.

\section{Correspondence:}

Katibe Tuğçe Temur

Department of Oral and Maxillofacial Radiology

Faculty of Dentistry

Niğde Ömer Halisdemir University

Niğde $\backslash$ Turkey

e-mail: tugcetemur@ohu.edu.tr 